\title{
ТАКСОНОМИЯ ПОДХОДОВ К ФОРМИРОВАНИЮ СТРАТЕГИЙ: ЗНАЧЕНИЕ ДЛЯ ТЕОРИИ БИЗНЕСА И ПОНИМАНИЯ МАРКЕТИНГА В ДЕЯТЕЛЬНОСТИ ПРЕДПРИЯТИЙ
}

\author{
(c) 2021 Красюк Ирина Анатольевна \\ доктор экономических наук, профессор, Высшая школа сервиса и торговли \\ Санкт-Петербургский политехнический университет Петра Великого, Россия, Санкт-Петербург \\ E-mail: krasyuk_ia.@spbstu.ru \\ (c) 2021 Пашоликов Максим Александрович \\ кандидат экономических наук, доцент, Высшая инженерно-экономическая школа \\ Санкт-Петербургский политехнический университет Петра Великого, Россия, Санкт-Петербург \\ E-mail: vicerector.dm@spbstu.ru
}

В современных условиях актуализируются вопросы маркетингового управления, теория и методология которого базируется на маркетинговом конструкте управленческой деятельности. Маркетинговая направленность промышленных предприятий обусловлена интересами потребителей промышленного бизнеса, согласованность маркетинговых действий приводит к увеличению объемов продаж. Маркетинговое партнерство промышленных предприятий способствует дальнейшему развитию маркетинговых стратегий, достижению маркетинговых целей и оптимизации маркетинговых ресурсов для увеличения рыночного сегмента промышленного бизнеса. Целью исследования является определение возможностей интеграции между школами менеджмента и маркетингом. Для достижения данной цели была выполнена систематизация маркетинговых стратегий на рынке В2В. По результатам исследования были определены ключевые характеристики маркетингового взаимодействия.

Ключевые слова: маркетинговые стратегии, рынок В2В, маркетинговое управление, школы менеджмента, бизнес-модели.

Разработка и реализация маркетинговой стратегии в промышленном бизнесе занимает ключевое место в деятельности предприятий. За последнее время произошли фундаментальные изменения в теории и методологии, практике маркетингового управления деятельностью промышленного предприятия.

Проблемное поле нашего исследования лежит в области теории о стратегическом управлении, что позволяет сформулировать гипотезу о возможности и необходимости использования маркетинговой составляющей в качестве средства обеспечения конкурентных преимуществ промышленного предприятия.

По мнению Генри Минцберга и др.: «...Стратегический менеджмент представляется как циклический процесс, состоящий из трех отдельных, но последовательных фаз - формулирования, внедрения и контроля...» [2].

Методология стратегического управления постоянно эволюционирует, поэтому разработка методологических аспектов управления позволяет определить возможности его влия- ния на эффективность работы предприятия и оценить результаты прикладного применения. Необходимость разработки методологии маркетингового управления обусловлена отсутствием четких границ между понимаем категорий «управление маркетингом» и «маркетинговое управление» [4]. Наша авторская позиция заключается в том, что маркетинговое управление имеет комплексный характер и является результатом интеграции управления и маркетинга. Глобализация рынка оказала влияние на сферу реализации маркетингового управления, которое может рассматриваться как методологический базис применения маркетингового подхода к управлению промышленными предприятиями. Кроме того, маркетинговое управление имеет стратегическую направленность, концептуальный характер которого определяется методологическими положениями стратегического маркетинга и стратегического управления. Системный характер методологии маркетингового управления зависит от структуры, соответствующей приоритетам страте- 
гического управления промышленными предприятиями в соответствии с поставленными задачами. Следовательно, методология маркетингового управления соответствует методологии управления и представляет собой одну из его разновидностей.

Актуализация теории и методологии маркетингового управления обусловлена маркетинговой ориентацией промышленных предприятий, в основе которой потребности, интересы и цели. Маркетинговая ориентация промышленных предприятий - это контент развития промышленного бизнеса. Онтология управления заключается в том, что субъекты и объекты управления промышленного рынка поэлементно и структурно связаны с маркетинговым подходом к управлению организацией. Структуризация маркетингового управления предполагает определение границ на уровне: предприятия, отрасли, региона, страны, мирового сообщества. Принципы маркетингового управления определяют условия осуществления маркетинговой деятельности, оказывают влияние на выбор цели и формирование миссии промышленного предприятия. Маркетинговая платформа промышленной деятельности предусматривает проведение оценки маркетинговой ситуации, ресурсного потенциала и определение маркетинговых возможностей дальнейшего развития. Маркетинговая стратегия связана с завоеванием и поддержанием конкурентного преимущества, способствует развитию промышленного бизнеса. Систематизация маркетинговых стратегий, используемых на рынке В2В, представлена в таблице 1 .

Клиентоориентированные стратегии маркетинга направлены на потребителя, формат их действия предусматривает комплекс маркетинговых мероприятий по увеличению жизненного цикла целевого клиента (C-suite). Применение технологий Influencer-маркетинг позволяет овладеть умом и настроением потребителей, охватить новую аудиторию. Применение клиентоориентированных стратегий расширяет возможности бизнеса по переориентации посредством вложения маркетинговых инвестиций в жизненный цикл клиента, в результате принимаются маркетинговые решения, направленные на удержание целевых и приобретение новых клиентов, улучшается клиентоориентированность.

Информатизация бизнеса предусматривает использование технологий цифрового маркетинга, формирование привлекательного контента. Капитализация социальных платформ оказывает положительное влияние на управление взаимоотношениями с клиентами, способствует формированию положительного имиджа и улучшает восприятие бренда.

Для рынка В2В характерны интеграция, кооперация и маркетинговое взаимодействие посредством переопределения отношений с канальными партнерами, реализации стратегии омниканальности; что в результате создает условия для канальной модификации и функционирования партнерских программ.

Таблица 1. Маркетинговые стратегии на рынке В2В [6]

\begin{tabular}{|c|l|l|}
\hline № & \multicolumn{1}{|l|}{ Область реализации маркетинговой стратегии } & \multicolumn{1}{|c|}{ Маркетинговый результат } \\
\hline 1 & $\begin{array}{l}\text { Маркетинговые решения } \\
\text { C-suite } \\
\text { Influencer-маркетинг } \\
\text { Маркетинг удержания } \\
\text { Приобретение }\end{array}$ & $\begin{array}{l}\text { Улучшение клиентоориентированности } \\
\text { Контентного маркетинга }\end{array}$ \\
\hline 2 & $\begin{array}{l}\text { Клнтентный маркетинг } \\
\text { Социальный маркетинг } \\
\text { Построение бренда } \\
\text { Позиционирование бренда }\end{array}$ & $\begin{array}{l}\text { Сотрудничество через каналы } \\
\text { Канальная модификация } \\
\text { Омниканальность } \\
\text { Работа через канал } \\
\text { Стремление к канальности } \\
\text { Партнерские программы }\end{array}$ \\
\hline 4 & $\begin{array}{l}\text { Качество лидогенерации } \\
\text { АВМ } \\
\text { Работа с лидами } \\
\text { Согласование маркетинга }\end{array}$ & Максимизация реализации \\
\hline
\end{tabular}


Маркетинговый конструкт управленческой деятельности на рынке В2В максимизирует реализацию посредством лидогенерации, использования технологий маркетинга ключевых клиентов (ABM), что обуславливает согласованность маркетинговых действий и приводит к увеличению количества продаж.

Маркетинговое партнерство промышленных предприятий способствует дальнейшему развитию маркетинговых стратегий, достижению маркетинговых целей и оптимизации маркетинговых ресурсов для увеличения рыночного сегмента промышленного бизнеса.

Социализация промышленного бизнеса обуславливает приоритетность корпоративной и социальной ответственности. Использование технологий CSR позволяет подключиться к клиентам на эмоциональном уровне, что создает «эффект детонации», в основе которого реализация программ об экологии и социальных корпоративных программ для сотрудников.

В зависимости от ситуации на промышленном рынке могут быть реализованы разные маркетинговые стратегии. Увеличение рыночного спроса обусловлено интенсивностью потребления и поиском новых покупателей. Поэтому возможно использование стратегий:

- проникновения на рынок (потенциальные потребители, которые не пользуются данным товаром, хотя могли бы это делать);

- создания нового сегмента рынка (новые потребители, которые никогда не пользовались товаром);

- географической экспансии (поиск потребителей, которые находятся за пределами доступности каналов распределения).

Увеличение частоты потребления на промышленном рынке нерационально, так как требует дополнительных возможностей по развитию промышленного бренда и поиска новых способов использования промышленной продукции.

Гипотетическая структура рынка по мнению Ф.Котлера должна содержать следующие пропорции [1]:

- лидер рынка - 40\%;

- претендент на лидерство - 30\%;

- последователь - 20\%;

- обитатели ниш - $10 \%$.

Промышленные предприятия, имеющие статус доминирующей компании - лидера рынка для сохранения своих позиций должны постоянно осуществлять инновационную деятельность, что позволяет им увеличивать конкурентную силу и повышать эффективность производственной деятельности. Лидеры рынка, реализуя стратегию опережающего маркетинга, в удовлетворении потребностей клиентов используют технологии:

- гибкого маркетинга;

- упреждающего маркетинга;

- креативного маркетинга.

Работая на опережение промышленные предприятия, обладают высокой адаптивностью к изменившимся тенденциям промышленного рынка, креативностью мышления, позволяющей реализовывать инновационные решения.

Лидеры рынка для укрепления своих позиций на рынке, могут проводить стратегию оборонительного маркетинга, реализация которой предполагает применение шести оборонительных тактик:

- позиционная оборона;

- защита флангов;

- упреждающая оборона;

- контратака;

- мобильная оборона;

- вынужденное сокращение [1].

Компании, которые не являются лидерами на промышленном рынке, занимающие второе место, называют преследователями или претендентами на лидерство. Компания-претендент может начать наступление на лидера, на близкие по размерам компании-конкуренты или на небольшие местные и региональные фирмы. Компания-претендент реализует одну из пяти стратегий:

- фронтальное наступление;

- фланговая атака;

- окружение;

- обходной маневр;

- партизанская война [1].

Не менее результативной является применение технологий имитации товара. Внедрение нового товара на рынке предполагает значительные финансовые затраты на разработку нового товара и организацию его маркетингового сопровождения по внедрению на рынок. Компании-последователи, копируя промышленный товар могут получать прибыль, так как они не несут расходы по созданию и продвижению нового продукта. Компании-последователи могут полностью копировать товар или вносят некоторые изменения в упаковку и рекламные 
мероприятия.

Лидерство на ограниченном рынке или в рыночной нише способствует уменьшению конкуренции со стороны крупных компаний. Обитатели ниши (нишеры) имеют возможность получить высокую прибыль за счет увеличения размеров рынка. Однако рыночный потенциал ниши может быть исчерпан или со временем занят конкурентами. Промышленным компаниям-нишерам желательно использовать множественную специализацию:

- по конечным пользователям;

- по вертикали;

- по значимости покупателей;

- на особых клиентах;

- географическая;

- товарная;

- на производстве товара с определенными характеристиками;

- на индивидуальном обслуживании клиентов;

- на определенном соотношении цена/качество;

- на обслуживании;

- на каналах распределения [1].

Позиционирование промышленных компаний базируется на реализации маркетинговых стратегий. Анализ промышленного рынка позволяет оценить покупательские предпочтения, характер конкуренции, перспективы развития различных отраслей промышленности.

Деятельность промышленных предприятий в условиях конкурентного рынка предусматривает использование ресурсного потенциала и применение маркетингового подхода. Маркетинговый подход в деятельности промышленных предприятий концептуально базируется на реализации маркетинговых стратегий, направленных на достижение целей маркетинга и укреплении конкурентных позиций. Маркетинговая стратегия - это программа предприятия, направленная на достижение маркетинговых целей посредством продвижения промышленной продукции, удовлетворяющей потребностям потребителей [4].

Развитие экономических отношений и появление «нового потребителя» усложнило конкурентную среду предприятий, что послужило стимулом развития дифференциальных подходов к формированию маркетинговой страте- гии предприятия, который ориентировался на углубленное внимание к интересам конкретных отраслей и сфер деятельности. По мнению М.Портера «...стратегия представляет собой создание-посредством разнообразных действий-уникальной и ценностной позиции [5]».

При такой модели формирования маркетинговой стратегии делается упор на правильном позиционировании компании - вхождении на рынок «правильной отрасли» или подотрасли. Специфика отрасли позволяет спрогнозировать маркетинговую деятельность компаний в разных отраслях, включая выработку тактических действий и экономическую результативность. Эффективность маркетинговой деятельности промышленных предприятий в пределах одной отрасли зависит, не только от отраслевых, но и от других факторов и возможностей, в том числе эффективности работы ее руководителя. Маркетинговое управление промышленными предприятиями позволяет рассматривать стратегию как перспективный план маркетинговых действий. Стратегическое планирование в маркетинге связано с процессом стратегического управления, в таблице 2 представлен авторская точка зрения на интеграцию стратегий, разрабатываемых в рамках школ менеджмента, к маркетинговой деятельности промышленного предприятия.

В настоящее время маркетинговая ориентация предприятий определяет содержание рыночной и производственной политики промышленного предприятия, основе которой маркетинговый подход. Систематизация и технологичность применения маркетингового инструментария позволяют достичь положительных маркетинговых результатов. Формирование стратегии как процесса создания бизнес-модели позволяет формировать дизайн для бизнес-моделей будущего. Предлагаемая авторами школа маркетинга (школа маркетингового управления) предусматривает разработку и реализацию маркетинговых стратегий бизнес-моделирования, конечным продуктом которых будет создание нового рынка, предлагающего ценностное предложение посредством фундаментальной дифференциации с помощью реализации инновации ценности. 
Таблица 2. Интеграция школ менеджмента и маркетинга [авторская разработка]

\begin{tabular}{|c|c|c|c|}
\hline № & $\begin{array}{l}\text { Название } \\
\text { школы }\end{array}$ & $\begin{array}{c}\text { Основная идея } \\
\text { разработки стратегии по } \\
\text { Минцбергу [3] }\end{array}$ & $\begin{array}{c}\text { Возможность применения } \\
\text { в маркетинговой деятельности }\end{array}$ \\
\hline 1 & Школа дизайна & $\begin{array}{l}\text { Формирование страте- } \\
\text { гии как процесс осмыс- } \\
\text { ления }\end{array}$ & $\begin{array}{l}\text { Маркетинговая стратегия } \\
\text { направлена на разработку новых продуктов; оценка ры- } \\
\text { ночной ситуации проводится на основе методики SWOT-a- } \\
\text { нализа; характеризуется персональной ответственностью } \\
\text { исполнителей }\end{array}$ \\
\hline 2 & $\begin{array}{l}\text { Школа плани- } \\
\text { рования }\end{array}$ & $\begin{array}{l}\text { Формирование страте- } \\
\text { гии как формальный } \\
\text { процесс }\end{array}$ & $\begin{array}{l}\text { Маркетинговая стратегия } \\
\text { направлена разработку маркетинговых программ и планов, } \\
\text { ответственность за выполнение которых несут маркетинго- } \\
\text { вые структуры. }\end{array}$ \\
\hline 3 & $\begin{array}{l}\text { Школа позици- } \\
\text { онирования }\end{array}$ & $\begin{array}{l}\text { Формирование страте- } \\
\text { гии как аналитический } \\
\text { процесс }\end{array}$ & $\begin{array}{l}\text { Маркетинговая стратегия } \\
\text { направлена на поиск перспективных } \\
\text { рыночных сегментов и определение товаров-звезд. Оценка } \\
\text { рыночной ситуации проводится при помощи матрицы БКГ. }\end{array}$ \\
\hline 4 & $\begin{array}{l}\text { Школа пред- } \\
\text { приниматель- } \\
\text { ства }\end{array}$ & $\begin{array}{l}\text { Формирование страте- } \\
\text { гии как процесс предви- } \\
\text { дения }\end{array}$ & $\begin{array}{l}\text { Маркетинговые решения принимаются на основе инно- } \\
\text { вационной идеи, в основе которой инновационная идея, } \\
\text { базирующаяся на творческом подходе и интуиции предпри- } \\
\text { нимателя. Разработка гибких адаптивных маркетинговых } \\
\text { решений. } \\
\text { Реализация конкурентных стратегий маркетинга (виолент- } \\
\text { ной, патиентной, коммутантной и эксплерентной). }\end{array}$ \\
\hline 5 & $\begin{array}{l}\text { Когнитивная } \\
\text { школа }\end{array}$ & $\begin{array}{l}\text { Формирование стра- } \\
\text { тегии как ментальный } \\
\text { процесс }\end{array}$ & $\begin{array}{l}\text { Использование технологий маркетинга C-suite, направлен- } \\
\text { ных на разработку стратегических маркетинговых решений, } \\
\text { Построение маркетинговой архитектуры деловых отноше-- } \\
\text { ний, формирование ценностных предложений. Реализация } \\
\text { стратегии кооперации }\end{array}$ \\
\hline 6 & $\begin{array}{l}\text { Школа обуче- } \\
\text { ния }\end{array}$ & $\begin{array}{l}\text { Формирование страте- } \\
\text { гии как развивающийся } \\
\text { процесс }\end{array}$ & $\begin{array}{l}\text { Использование технологий внутреннего маркетинга, на- } \\
\text { правленного на решение вопросов, связанных с наймом, } \\
\text { обучением и мотивацией сотрудников. В основе обучения - } \\
\text { стержневые компетенции. Реализация стержневой страте- } \\
\text { гии. }\end{array}$ \\
\hline 7 & Школа власти & $\begin{array}{l}\text { Формирование страте- } \\
\text { гии как процесс ведения } \\
\text { переговоров }\end{array}$ & $\begin{array}{l}\text { Применение технологий } \\
\text { политического маркетинга (маркетинг власти), позволяю- } \\
\text { щих объединить различные точки зрения на маркетинговой } \\
\text { платформе, и направить результаты данной интеграции } \\
\text { для разработки и формирования маркетинговой стратегии } \\
\text { покупательского контингента. Реализация стратегии инди- } \\
\text { видуализации потребителя. }\end{array}$ \\
\hline 8 & $\begin{array}{l}\text { Школа куль- } \\
\text { туры }\end{array}$ & $\begin{array}{l}\text { Формирование страте- } \\
\text { гии как коллективный } \\
\text { процесс }\end{array}$ & $\begin{array}{l}\text { Использование технологий корпоративного маркетин- } \\
\text { га, направленных на привлечение клиентов; разработку } \\
\text { маркетинговых программ по организации работы с потен- } \\
\text { циальными клиентами и выбора различных форм комму- } \\
\text { никационного взаимодействия. Реализация корпоративных } \\
\text { маркетинговых стратегий. }\end{array}$ \\
\hline 9 & $\begin{array}{l}\text { Школа внеш- } \\
\text { ней среды }\end{array}$ & $\begin{array}{l}\text { Формирование стра- } \\
\text { тегии как реактивный } \\
\text { процесс }\end{array}$ & $\begin{array}{l}\text { Применение инструментария внешнего маркетинга, на- } \\
\text { правленного на разработку маркетинга-микс в соответствии } \\
\text { с изменениями внешней среды, адаптация маркетинговой } \\
\text { деятельности в соответствии с рыночными реалиями. Реа- } \\
\text { лизация стратегии завоевания части рынка или расширения } \\
\text { этой доли до оптимальных показателей. } \\
\end{array}$ \\
\hline 10 & $\begin{array}{l}\text { Школа конфи- } \\
\text { гурации }\end{array}$ & $\begin{array}{l}\text { Формирование страте- } \\
\text { гии как процесс транс- } \\
\text { формации }\end{array}$ & $\begin{array}{l}\text { Трансформация маркетинга в цифровой среде предусма- } \\
\text { тривает использование технологий интернет-маркетинга } \\
\text { для обеспечения маркетингового взаимодействия и инди- } \\
\text { видуализации маркетингового инструментария. Реализация } \\
\text { цифровой-стратегии. }\end{array}$ \\
\hline 11 & $\begin{array}{l}\text { Школа марке- } \\
\text { тинга } \\
\text { (маркетинго- } \\
\text { вого управле- } \\
\text { ния) }\end{array}$ & $\begin{array}{l}\text { Формирование страте- } \\
\text { гии как процесс созда- } \\
\text { ния бизнес-модели }\end{array}$ & $\begin{array}{l}\text { Применение технологий бизнес-моделирования, направ- } \\
\text { ленных на долгосрочные решения по формированию } \\
\text { ассортиментного портфеля, загрузке производственных } \\
\text { мощностей. Маркетинговые бизнес-модели нацелены на } \\
\text { определение потребностей целевого рынка, организацию } \\
\text { маркетингового сопровождения инновационных продуктов. } \\
\text { Маркетинговые стратегии бизнес-моделирования. }\end{array}$ \\
\hline
\end{tabular}




\section{Библиографический список}

1. Котлер Ф., Келлер К. Маркетинг менеджмент.-СПб.: Питер, 2019.-448 с.

2. Минцберг Г. Стратегическое сафари: Экскурсия по дебрям стратегического менеджмента/ Генри Минцберг, Брюс Альстранд, Жозеф Лампель; Пер. с англ. - 5-е изд.- М.: Альпина Паблишер, 2019._512 с.

3. Минцберг Г., Альстрэнд Б., Лэмпел Дж. Школы стратегий / Пер. с англ. под ред. Ю. Н. Каптуревского.- СПб.: Питер, 2001. 336 с.

4. Пасичник И.Ю. Оценка эффективности маркетинговой стратегии управления конкурентоспособностью продукции машиностроительных предприятий//Фундаментальные исследования. № 11-8. 2003. с. 16661669.

5. Портер Е. М. Конкурентная стратегия: Методика анализа отраслей и конкурентов / Портер E. M.; [пер. с англ. И. Минервин].-- М.: Альпина Бизнес Букс, 2005.- 454 с.

6. Холл, Саймон В2В-продажи: как построить эффективную систему продвижения.- Москва: Эксмо, 2020.448 c. 